\title{
UMA POLÍTICA DA VÍTIMA: \\ A LITERATURA BRASILEIRA, O QUARUP DOS VENCIDOS
}

\author{
POR \\ ROBERTO VECCHI \\ Università di Bologna
}

O romance de Antônio Callado, Quarup (1967), não é só um dos grandes livros da literatura brasileira. Mesmo que o presente texto não se debruce analiticamente sobre a narrativa da história traumática do Brasil-do suicídio de Getúlio ao golpe civilmilitar de 1964-, retratado por Callado, uma observação é oportuna antes de focalizar a atenção sobre um tema implicado também por este romance: o lugar da vítima na escrita contemporânea brasileira. Quarup não contribui somente para fundar uma relação peculiar entre literatura e política, tanto ao representar uma página conturbada da história nacional, como no sentido convencional que Jacques Rancière configura, ou seja, de como a literatura faz política enquanto literatura (13). Mas sobretudo porque proporciona um dispositivo com que repensar a literatura brasileira como um lugar específico de resgate político das vítimas, numa linha divergente em relação ao que ocorre no plano da efetividade histórica. É como se a literatura oferecesse uma dimensão política suplementar e alternativa em relação à realidade, onde se podem abrigar sujeitos marginais desprovidos de qualquer rastro histórico e, portanto, fadados a serem excluídos de qualquer possibilidade historiográfica. É como no caso, por exemplo, das vítimas e do risco permanente de um seu apagamento histórico.

Mas por que falar, hoje, da vítima na literatura com uma potência ao mesmo tempo negativa e positiva que marca em profundidade o nosso tempo? De fato, há um espetro que roda pela literatura, não só brasileira, não só contemporânea. Esse espetro é a vítima. E limitar o campo exclusivamente ao literário talvez seja redutor de uma questão na verdade bem mais ampla e articulada.

A crítica da vítima produz, de imediato, um sentimento de constrangimento. É a partir deste constrangimento que é interessante pensar porque justamente aí surge o problema que podemos definir como a "mitologização" da vítima. Pode-se criticar a vítima? Ou sua vulnerabilidade a preserva a priori de qualquer crítica não só ontológica mas que afete também seu estatuto de objeto representacional? As perguntas parecem retóricas e parecem supor mecanicamente uma negativa: a crítica da vítima, desde 
logo, parece incorreta e injusta, ou pelo menos supor uma leviandade de consciência que proporciona uma sobrecarga gratuita ao aprontar com ela, a vítima, o avesso do paradigma heroico.

Esta reserva é o fruto de um processo complexo-mas também ao mesmo tempo lógico-que combina sofrimento e sentimento de culpa. Esses se intersectam num jogo de espelhos que faz com que, nota Esther Benbassa estudando nesta perspectiva a construção histórica da identidade judaica, "o sofrimento [crie] a vítima e o fato de ser vítima se [transforme] em uma atitude moral" (10), o que abre o espaço para a construção de uma ética do sofrimento dos outros, só aparente e desinteressada em aprofundar mesmo a experiência da vítima. Isso ocorre porque a vítima é uma figura complexa, difícil de apreender em todos seus aspectos, inclusive no plano etimológico.

Deste ponto de vista, a origem e o significado do termo variam muito e de modo contraditório embora com alguns elementos comuns associáveis à esfera do sagrado: é derivado de "victus", não só como particípio no sentido imediato de vencido, mas também na acepção substantival de alimento oferecido em sacrifício aos deuses, ou no sentido de "ligado" sempre na perspectiva sacrificial, mas pode ter origem também, por oposição, em "victoria" porque se imolavam as vítimas para as divindades para celebrar justamente o êxito de um evento bélico e, ainda dentro da opacidade do termo, pode caber também o verbo "vigere" no significado de ser forte, porque o que se sacrificava eram as melhores cabeças dos animais.

A oscilação semântica é ampla expondo desde logo uma ambivalência que talvez possa proporcionar um acesso linguístico a algumas das questões substanciais que alimentam a discussão crítica hoje por volta da vítima, ou melhor sobre seu uso escorregadio no plano das representações. De fato, nos últimos anos, se abriu e está em andamento um debate na Europa (França e Itália, para citar dois casos mais evidentes) não tanto sobre o respeito pelas vítimas reais, mas muito mais sobre o uso das vítimas por parte da mídia e dentro de diferentes âmbitos das representações culturais.

Se a vítima civil se integra numa genealogia moderna constituída no século XIX (e cujos primeiros rastros-representativos e já de certo modo politizados-se podem detectar na experiência da Comuna de Paris [Mesnard 91] enquanto sua existência jurídica surge, por subtração, a partir da "Declaração dos Direitos do homem e do cidadão" [Penna 95]), a discussão da vítima como "máquina mitológica" (adotando o conceito de Furio Jesi de uma mitologia que possibilita uma ciência da mitologia e dos seus materiais versus o uso ideológico do mito [Jesi 106]) remonta aos últimos anos. Isso ocorre sobretudo se se apoiou em trabalhos como os de Mesnard que discutem a paisagem humanitária e o uso da vítima enquanto seu elemento fundamental, mostrando como suas representações respondem predominantemente a lógicas de mercado e se viram para uma reconfiguração do poder e das suas declinações simbólicas, mais do que implicam um efetivo interesse pelas vítimas e pelos inermes (Mesnard 13).

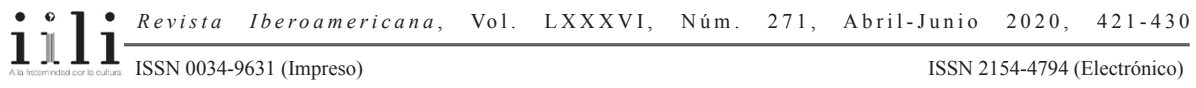


Uma discussão análoga talvez ainda mais aguçada ocorreu nos últimos anos na Itália sobretudo depois da publicação do ensaio Critica della vittima de Daniele Giglioli (2014). O objeto da revisão não são as vítimas reais, mas como o imaginário da vítima, na linha de Mesnard, se converteu em um "instrumentum regni" que decorre de uma mitologização-ou falsificação-da vítima (Giglioli 12). O silêncio é constitutivo da vítima: ela pode atuar discursivamente como uma figura retórica-uma prosopopeia conferindo a palavra aos objetos inanimados-que evidencia ainda mais a artificiosidade da sua fala. Ocorre no discurso vitimário-para usar uma expressão que não se confunda com o vitimismo-uma substituição porque "quem fala como vítima ou pela vítima se encontra sempre na situação de quem fala no lugar de um outro" (Giglioli 17).

A fala da vítima assim se insinua naquele tecido problemático da representação vicária que ocupa larga parte da reflexão contemporânea (a testemunha, o tradutor, o subalterno, o autor, etc., isto é, todos os sujeitos que desempenham a tarefa de representar discursivamente uma parte da relação com a responsabilidade de representar a outra parte, aquela que falta). De acordo com Giglioli, a posição da vítima (vicária e discursiva) confere uma forma de poder singular, numa espécie de troca de potência nos tempos da crise da democracia participativa (27). Será isso que lhe confere o sucesso mediático contemporâneo? Porque a vítima, na verdade, é a primeira vítima desta mitologização vitimária que lhe subtrai força e a entrega a uma instância outra, de oráculo problematicamente legítimo como "porta-voz" de um silêncio intransitivo, como é sempre aquele produzido pela experiência da dor e do sofrimento.

Pelo contrário, a vítima se identifica não por um suplemento, mas por uma falta (jurídica, representativa, de recursos, de bem-estar ou de vida): ela se torna em suma "um bem pelo avesso" (Giglioli 88) que desmente uma ética que se estrutura a partir da sua mitologização e que procura na imagem uma mera possibilidade de se espelhar.

Há um magnífico ensaio de João Camilo Penna que já foi citado, "Poética da vítima", onde se instaura uma problemática identificação entre a vida nua, o homo sacer agambeniano, e a vítima, duas figuras-de diferente natureza-que aparentemente se poderia pensar que coincidem. Na reconstrução de Penna, os dois planos se mantêm distintos e mostram como a vítima surge a partir de sua reconfiguração cultural posterior: "O homem sacro é proscrito tanto da lei dos deuses quanto da dos homens, enquanto a vítima é constituída como sujeito de direito. Este deslizamento, no entanto, já é percebido na própria origem romana da figura do homo sacer: a proscrição do direito não impede que a lei legisle après coup sobre o assassinato do proscrito, produzindo leis, a partir de algo que não tem figuração jurídica" (95).

Uma diferença que se sanciona, também dentro deste raciocínio, no deslize do termo Shoah para o termo, na aparência impróprio, de Holocausto: isso ocorre no momento em que o genocídio hebraico é convertido em princípio de restituição para os vivos e "é aqui que o homo sacer, como quantum não-figurável e não-significável de dor, se transforma em vítima" (Penna 96).

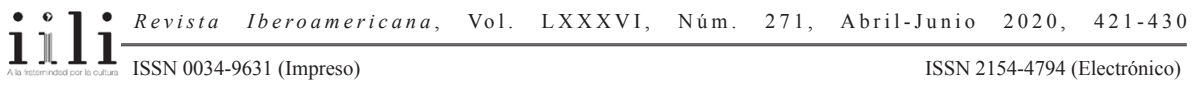


Na representação vitimária, a vítima não encontraria, portanto, inscrição. Também considerando outra etimologia interessante: os vitimários, como substantivo, eram na Roma antiga as pessoas subalternas deputadas à ação sacrificial; eram eles que conduziam a vítima na ara, no altar, e que a matavam e esquartejavam para executar o ritual, deixando uma parte como oferta para os deuses. Será esse o papel dos autores que recorrem às vítimas para a construção de uma representação própria do sofrimento?

Situando o problema no nosso contexto agora é oportuno nos perguntarmos se a literatura brasileira pode se definir como uma literatura vitimária ou se sua relação com a vítima é de outra natureza e, nesse caso, porquê.

Que a vítima ocupe historicamente um lugar proeminente na literatura brasileira é quase escusado dizer. ${ }^{1}$ Numa genealogia por defeito e diferença-e também imediatapenso em obras necessariamente complexas quanto à definição instrumental das vítimas (retratadas como portadoras de perversões infindáveis-nesse caso o escravo-portanto em pleno, vitimária) como As Vitimas-algozes. Quadros da Escravidão, de Joaquim Manuel de Macedo. Mas pela colagem de cacos de Brasis canonicamente extintos e desfocados, surgem grandes fragmentos literários: de alguns trechos aparentemente periféricos mas cruciais de Machado de Assis, às passagens mais diretas dos embates "pré-modernistas" em autores como Afonso Henriques de Lima Barreto, recortes de Vidas Secas ou das Memórias do cárcere de Graciliano Ramos ou de Grande sertão de Guimarães Rosa ou da A menina morta de Cornélio Penna ou dos Severinos de João Cabral de Melo Neto, passando por Quarup de Callado (que inspirou estas considerações), Em Câmara lenta de Renato Tapajós ou a K. de Bernardo Kucinski, como sinais ou rastros de uma outra estação autoritária, para chegar à literatura das periferias como fenômeno que reproblematiza a vocalização da vítima.

No centro desta constelação parcial que remete na verdade para uma história literária alternativa, se situa com certeza o livro que é radical e substancialmente dedicado à refundação da vítima e do pensamento da vítima, que é, obviamente, Os Sertões de Euclides da Cunha. Sem querer me deter nesse livro cada vez mais surpreendente, é nele que ocorrem algumas operações teóricas chave para a inscrição da vítima na literatura brasileira. Enumero de forma muito esquemática as mais evidentes: a reconfiguração de todos os saberes em função da perspectiva das vítimas do massacre, a troca precoce do paradigma heroico com um paradigma vitimário (aliás, não uma substituição, mas uma inversão seca) o impasse trágico na assunção completa da voz do outro, o caráter indiciário e nunca por inteiro constituído de uma narração da subalternidade, a história

1 O tema da vítima na literatura brasileira, a partir das implicações teóricas que pressupõe, foi objeto de uma conferência proferida em Brasília no "VI Simpósio Internacional sobre Literatura Brasileira Contemporânea: lugares e disputas", 2 a 5 de novembro de 2014. Retomo aqui alguns tópicos daquela apresentação e agradeço em particular a Regina Dalcastagnè pelas sugestões e comentários. Agradeço também a Nicola Gavioli pela discussão e a revisão de uma parte substancial deste texto. 
ruinosa para as vítimas que se transformam em bodes expiatórios da modernização autoritária, o desfalecimento da literatura como "sorriso da sociedade" (na canônica visão de Afrânio Peixoto) ou ornamento elitista e sua refuncionalização como cenotáfio ou memorial de rastros de outro modo condenados à extinção e ao recalcamento.

A lição que se depreende destas obras-como em algumas outras-é que o lugar da vítima na literatura é alvo de uma tentativa tão intensa que transcende os limites do campo vitimário, pretendendo bem mais se tornar-pelo menos a um nível idealístico mas também nas praxes que desse nível decorrem-uma literatura "da" vítima. No sentido pleno, objetivo mas também subjetivo do genitivo: uma literatura que pertence à vítima e que tem ela como sujeito.

Essa tendência literária que se afirma, talvez só como um gesto tragicamente votado para a derrota, remete a meu ver-e me perdoem o exercício culturalista que esboçopara um oco ou um vazio da vítima no plano social. Fora da literatura e dentro da vida, a vítima se torna socialmente uma não inscrição, se expõe pela sua indecidibilidade. A impressão surge quando pensamos em alguns fatos trágicos da história do Brasil, me refiro, a puro título de exemplo, à mobilidade da figura do escravo (ou ex-escravo) que representa, dentro da sociabilidade freyriana, o amigo-inimigo incessantemente oscilante entre os dois polos, ou, em épocas mais recentes, o opositor do regime militar que se constitui como inimigo ("interno") e não vítima de uma outra violência política. Me atreveria, portanto, a assinalar um regime pelo menos duplo da vítima cujas raízes talvez decorram de efeitos profundos de relações de violência oriundas da experiência da colonialidade.

Aliteratura brasileira, ou -como dissemos-a parte clássica dela, tem desenvolvido, no entanto, na falta ou no oco de uma inscrição da vítima, o papel de consciência crítica da modernização do País, da violência dos processos assimilatórios e de dominação, da construção hegemônica e autoritária de narrativas nacionalistas que se espelhavam em modernidades externas e alheias. Por um lado, próxima do poder das elites que se conservaram das antigas capitanias hereditárias, inclusive dentro uma independência paradoxalmente imperial, mas, por outro lado, consciência crítica e inconformada contra as consagrações das retóricas do poder, das miopias e restrições inclusive interpretativas sobre a nação: a não coincidência entre a pátria declamada e a nação real, esta última marcada por graves abusos, lesões, subtrações da cidadania.

A literatura da vítima, portanto, como se pode bem intuir também do romance de Callado, se insinua sempre em uma perspectiva que não pode deixar de ser genealógica, sendo a genealogia, como sugere Michel Foucault, a articulação do corpo e da história e deve mostrar o corpo todo marcado pela história: a história que devasta o corpo (37).

Qual é, portanto, esta articulação na escrita contemporânea? A questão evidentemente exige um grau crítico que ultrapassa as limitações deste ensaio. Ao mesmo tempo é importante ressaltar que desde a década de 90, se multiplicaram as tentativas de inscrever a vítima no campo literário, confirmando assim sua ausência ou

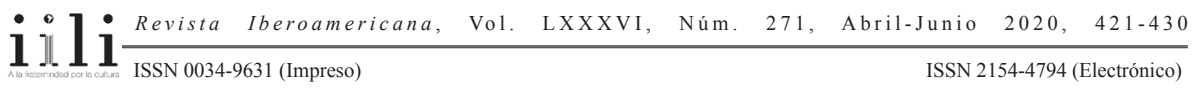


falta em outros tipos de discursos públicos. Ao mesmo tempo, esta literatura que procura necessariamente promover uma política de restituição, talvez se tenha embatido com a aporia da representação da vítima que, como se dizia, é por natureza de caráter vicário, por interposta pessoa, por mediação. Ou seja, a vítima real se constitui-inclusive em um plano ontológico-a partir de uma impotência inclusive de fala, porque sua agência é inexoravelmente "castrada" (Giglioli 89): de outro modo, ela deixaria de ser vítima real e se tornaria vítima imaginária e portanto facilmente fetichizável. A natureza da escrita literária, portanto, expõe a representação da vítima a um constante risco oscilando entre estas duas possíveis posições, o plano efetivo e o plano fictício sempre da vítima.

Aliteratura marginal, que inclui na escrita literária um imenso patrimônio periférico de outro modo excluído, ao mesmo tempo tornando-se escrita também vitimária, cai nas limitações, pelo menos neste caso, do que podemos chamar da aporia trágica de Graciliano. Isto é, o fracasso da tentativa de criar uma narrativa de grau zero em termos de subjetividade do narrador para assumir a voz do excluído, mas expondo na realidade, na própria tentativa, sua trágica inviabilidade. O problema, esse, que pauta de modo geral e permanente as relações entre intelectual e povo, uma fratura não componível entre a distinção clássica de Darstellung e Vorstellung, entre apresentação e representação. Do outro, da vítima, do vencido.

Acrescenta-se também outra aporia que investe em pleno a questão ética da vítima. Num ensaio famoso, Alain Badiou ao tratar da ética e do mal (1994) contesta a partir da vítima, a proposição de acordo com a qual o homem é quem é capaz de reconhecer a si próprio como vítima (14), ideia que decorre da suposição de um Sujeito humano universal. O que ocorre com o testemunho da (em nome da?) vítima, no entanto, observa o filósofo francês, é que exige um ato inaudito que rompa a identidade com a vítima (15). Isso ocorre quando ele se desloca mostrando que é outro em relação à vítima, outro em relação ao ser-pela-morte, portanto outro em relação ao mortal (15).

Aabordagem, baseada na impossibilidade irredutível de identificação com a vítima, é polêmica mas tem indícios úteis para problematizar o eixo entre a literatura vitimária e a literatura, por assim dizer, da vítima, considerando que esta última se apoia numa aporia de certo modo trágica.

Essa discussão encontra, a meu ver, em uma obra aparentemente disjunta em relação a essa problemática, uma base de questionamento muito ampla. Refiro-me a um romance sobre o qual se estão acumulando bastante leituras críticas, Passageiro do fim do dia de Rubens Figueiredo, de 2010, que quero usar como base para discutir o tema só aparentemente lateral da vítima.

Tudo ocorre pela costura de uma dupla dimensão que produz uma ambivalência essencial na narrativa entre um fora dos contextos onde normalmente se situa a escrita periférica, mas ao mesmo tempo um dentro-um dentro profundo-desse contexto. Tal efeito é proporcionado pelo elemento dinâmico que se inscreve na narrativa e que

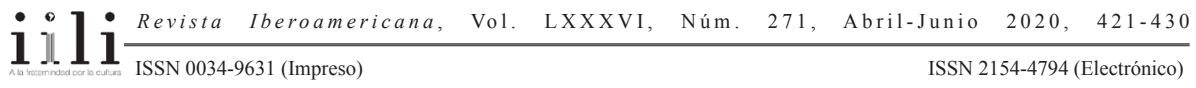


decorre da passagem pelo ônibus do protagonista, Pedro, dono de um sebo no centro da cidade, que se encontra em trânsito entre diferentes espaços, conectando centro e periferia e conseguindo o efeito pela qualidade engenhosa da narração, a resenhar os espaços e desmontá-los inclusive em suas dobras menos evidentes.

A narrativa que decorre dessa opção é, pela perspectiva do protagonista, drasticamente fraturada, embora a sequencialidade seja garantida também pelo próprio movimento físico na aparência linear do protagonista. As rupturas ocorrem através de um processo planejado de interrupção devido a fatores muito diferentes: o mais evidente é a leitura do livro sobre Darwin que inscreve um anacronismo que progressivamente se revela importante na economia da narração, as vozes que irrompem pelo rádio trazendo notícias globais e deslocalizadas, a memória em particular referida à cena de um trauma pessoal vivido (o episódio do cavalo da polícia militar que pisa no joelho da personagem), o convívio com Rosane no Tirol, um emblema de muitas periferias, as conjeturas e as especulações sobre os outros passageiros do ônibus, etc. A cena se fratura e se recompõe mas deixando expostas as linhas disjuntivas.

O livro, no entanto, não funciona como um texto vitimário ou até de certo modo vitimista. Não se esconde atrás das vítimas que passa em resenha porque, como sabemos, a vítima garante uma história (Giglioli 98) sobretudo em tempos dominados pelo storytelling onde todo mundo convém que a identidade individual e coletiva é uma identidade narrativa: porque a mitologia vitimária é "uma subalternidade que perpetua o domínio" (Giglioli 111-12).

Ao mesmo tempo, a narração redunda de "vítimas" de variada natureza: a própria Rosane, suas vizinhas e ex-colegas, "João" sem memória e parceiro de quarto do hospital depois do acidente do cavalo, meninos de rua. São fragmentos que flutuam e que não se compõem numa linha homogênea. Mesmo que tão presente, a vítima não se torna véu que fetichiza a vítima real (ontologicamente constituída por faltas, cacos, subtrações). Ao mesmo tempo, também a narrativa não perde coerência porque há uma rede de fios sutis que, por um jogo de associação ou conotações ou citações parciais e precárias, deixa tecer uma teia de remessas: basta uma linha do livro, uma tatuagem, uma marca, para voltar à teia latente que no entanto funciona como um conector poderoso de partes na aparência autônomas. O ponto mais evidente nesse sentido é quando ocorre a convergência entre a vítima-a amiga de Rosana, colega de escola noturna, que foi baleada com 17 anos, cujo corpo evoca "o meio de um livro aberto: o ponto onde a página par e ímpar afundam em curva e se unem na costura ou na cola por dentro da lombada" (Figueiredo 171). Eixo de muito eixos narrativos, o trecho não só dá uma consistência imagética ao corpo grafemático que possibilita outra narrativa através de um outro regime de signos próprio do corpo. Revela como, na falta e no vazio que contorna a vítima, só uma prática criativa de citações pode ativar uma possibilidade não vitimária de representação, não como prosopopeia do ausente, do subalterno, da vítima, mas como repolitização do texto por conexões impensáveis.

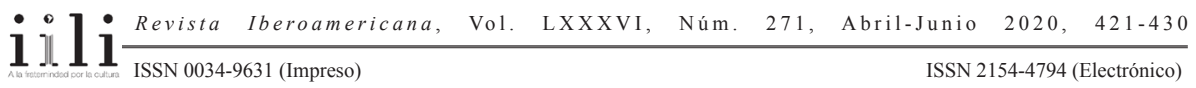


É assim que as interrupções, as intermitências, se tornam, diria com maior precisão, ainda que oximórica, "lacunas significantes" que reestruturam no vazio um sentido possível. Esse tipo de lacuna possibilita captar-lembrando a leitura de Penna sobre o uso da cesura e da parataxe na "poética da vítima"-"o irrepresentável do sofrimento do homo sacer, no instante em que ele se converte em vítima, isto é, em figuração do infigurável" (102).

No romance de Figueiredo, a construção estética procura provocar essa figuralidade paradoxal que permite abordar de forma positiva o problema do "irrepresentável" de Rancière. Acontece com as analogias (não antropológicas mas narrativas, ou seja, potencialmente falsas) que ocorrem no uso do anacronismo da visita ao Brasil de Darwin, seu choque perante o escravo que pelo uso de uma outra semântica social da violência, equivoca um gesto do cientista (66-67), o que abre o espaço para a construção da figura do desmemoriado "João".

No entanto, a escrita da vítima que contorna a limitação da representação vitimária se acentua com outras figuras de vítimas que permitem situar a atitude do protagonista que permeia o romance em relação à aporia representativa da vítima. Entre as múltiplas possibilidades vale a pena destacar o caso da própria Rosane quando é demitida depois do infortúnio na fábrica. Mas é também o caso da amiga anônima dela no desfecho do livro, cuja citação ou evocação ocorre depois de um outro contato sempre com a vítima; o caso da mãe da Flávia e da imaginação que produz a tatuagem que marca seu corpo ("Flávia, minha vida"). Os dois casos são dizíveis não em nome de uma solidariedade abstrata ou de uma assunção da vítima como garantia de construção de uma história "verdadeira e inocente" (como ocorre quando a vítima está em jogo [Giglioli 95 e 102]).

Mas por que o outro da vítima-nesse caso Pedro-se aproxima sem se confundir com a vítima? Seu contato é tão chegado que sensorialmente percebe os traços do corpo, mas a alteridade é inquestionável: "ele apertou Rosane de leve, com os dois braços. Sentiu os ossos por trás da pele quente, lisa-ossos articulados em várias direções, encolhidos, dobrados, quase por cima dele" (Figueiredo 160).

Assim como a vertente física da amiga sem nome de Rosane, baleada no tiroteio, com o corpo desfigurado, que funciona no entanto como rastro significativo (tanto que se torna signo e pode ser comparado a livro), emerge não pela voz, mas pelos sons imperfeitos que deixam entrever um sujeito, o murmúrio do outro-"Ele me ajudou muito-sorrindo, a moça esticava aquele 'muito', injetava um sopro e um calor no $m$ e no $u$, levantava um pouco a cabeça, estirando a duração da sílaba" (Figueiredo 167) -um "peso" sonoro que revela enquanto rastro: "Aquele muito da moça era carregado, pesava: não ia embora [...]. Alguma coisa tinha acontecido com ela mais cedo, naquele dia [...] alguma coisa que a obrigava a abrir a memória e falar" (Figueiredo 168).

A proximidade física-sensorial com a vítima permite, portanto, quebrar a identidade com ela e, surpreendentemente, através desta quebra, se pode flagrar ainda que por instantes-uma sobrevivência em suma-o rosto, o corpo, ou a voz dela. 
Este instante (aquele onde a vida nua se torna vítima) cria outros elos comunitários: se a dor é a experiência por definição singular e intransitiva, a consciência comum que surge da dor física como traço do humano-capaz de fundar uma memória própria mais resistente (Assmann 274)-permite uma representação precária, uma lacuna que produz um sentido, um resto que autoriza um testemunho ainda que lábil e quase apagado.

Lateral e literária, a citação-que pressupõe os mesmos problemas éticos do testemunho-da vítima se torna assim possível ainda que por palpites e instantes porque "se a verdade está nos olhos da vítima, a verdade coincide com a morte" (Giglioli 106), ou seja, com uma lacuna que não poderá ser nunca mais preenchida e significada.

O dizer precário da vítima põe o autor numa condição próxima de quem deve citar, de uma obra inteiramente inacessível, o fragmento que exemplarmente a vocalize: a literalidade, portanto, é impossível e sempre pressupõe uma diferença ou uma deslocação, exatamente como a vítima exige. Fingir a literalidade significaria criar o pressuposto da falsificação da escrita vitimária, mesmo que apoiada sobre indícios efetivos, mas que pelo contrário remetem não para o plano da vítima real, mas para aquele inconfiável das suas possíveis fetichizações.

Essa proximidade é uma espécie de disponibilidade para a escuta. Sinais também auditivos, sons que problematicamente se articulam. A escrita da vítima, pelo que se deduz da viagem de ônibus de Pedro-uma viagem enorme dentro do tempo e de múltiplos universos obscenos, fora da cena (em termos de representação), num espaço delimitado mas que se pode tornar inacabado-performa um gesto de aproximação dela que talvez corresponda à configuração de uma outra ética.

Não uma ética vitimária fundada sobre um universalismo abstrato e oportunista e não na singularidade de um rastro ainda que invisível ou escutável. Ali se situa a vítima no instante de seu transpasse no limiar da representação, mas que fica aquém de qualquer mitologia vitimizadora e que a torna tão problemática e inapreensivelmente o que é, como bem confirma e fecha-a amiga colega de Rosane: "Falava em voz baixa: não a voz de quem protesta, se lamenta, mas de quem pergunta para si mesma-a voz de quem cansou, já queimou até as cinzas e só quer entender como é possível" (Figueiredo 154). Essa fala neutra e passiva é aquela que faz emergir a instância rejeitada e precária mas terrivelmente própria e não de outros, da vítima.

Percebe-se bem que o romance de Figueiredo é simplesmente um objeto final e disperso daquela inexaurível genealogia dos vencidos que a literatura brasileira contribui a resgatar: um grande quarup, heterogêneo e resistente como o Quarup de Callado que, no entanto, mostra como não na sociedade ou dentro da história, mas na narrativa, no plano da ficção, a vítima encontra a possibilidade efetiva de ganhar um nome e uma voz: "Você é que é forte e que vai fazer a força do nome. De qualquer nome" (Callado 496).

A literatura brasileira: o quarup das vítimas.

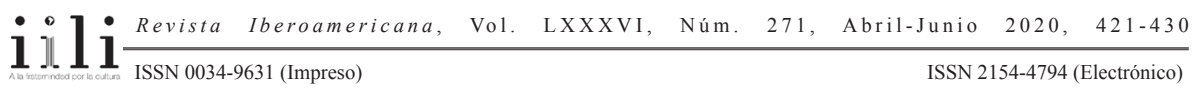




\section{OBRAS CITADAS}

Assmann, Aleida. Ricordare: forme e mutamenti della memoria culturale. Bologna: Il Mulino, 2002.

Badiou, Alain. L'etica: saggio sulla coscienza del male. Parma: Pratiche, 1994.

Benbassa, Esther. La sofferenza come identità. Verona: Ombre Corte, 2009.

Callado, Antônio. Quarup. 1967. Rio de Janeiro: Civilização Brasileira, 1982.

Figueiredo, Rubens. Passageiro do fim do dia. São Paulo: Companhia das Letras, 2010.

Foucault, Michel. "Nietzsche, la genealogia, la storia". Microfisica del potere. Giovanna

Procacci y Pasquale Pasquino, trads. Torino: Einaudi, 1977. 29-54.

Giglioli, Daniele. Critica della vittima. Roma: Nottetempo, 2014.

Jesi, Furio. Materiali mitologici: mito e antropologia nella cultura mitteleuropea.

Torino: Einaudi, 1979.

Mesnard, Philippe. Attualità della vittima: la rappresentazione umanitaria della sofferenza. Verona: Ombre Corte, 2004.

Penna, João Camillo. "Poética da vítima". Revista Brasileira II/74 (2013): 87-105.

Rancière, Jacques. Politica della letteratura. Anna Bissanti. Palermo: Sellerio, 2010.

Palavras-chave: Vítima; representação; discurso vitimário; Antônio Callado; Rubens Figueiredo

Recebido: $\quad 15$ novembro 2016

Aprovado: $\quad 15$ maio 2017

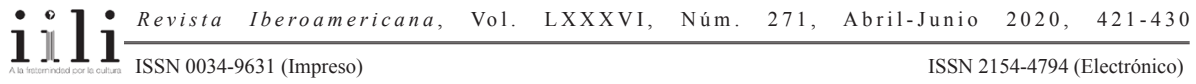

